\title{
Primary Pure Squamous Cell Carcinoma of the Breast Might Be Sensitive to Cisplatin-Based Chemotherapy
}

\author{
Swei H. Tsung \\ Department of Pathology, St. Mary's Hospital, Luodong, Taiwan, ROC
}

\section{Key Words}

Primary pure squamous cell carcinoma of the breast · Cisplatin

\begin{abstract}
Pure squamous cell carcinoma of the breast (PSCCB) is a rare condition. Surgery is usually the initial treatment. In some cases, complete excision of the tumor may be enough, while in other cases a mastectomy is required. In the literature, studies reported that PSCCB is an extremely aggressive disease associated with frequent locoregional and distant relapses and resultant death. Better therapy is therefore needed to improve patients' outcome. A literature review revealed that several patients with locoregional and distant metastasis were successfully treated using cisplatin-based regimens. I encountered a case of a patient with PSCCB who received neoadjuvant therapy using cytoxan, epirubicin, and fluorouracil without any response. Therefore, she underwent a mastectomy with lymph node dissection. Local recurrence occurred 3 weeks after surgery. She was started on taxotere and cisplatin. Four months after therapy, the recurrent tumors completely regressed. At this point, there is only circumstantial evidence that cisplatin-based regimens could be a promising option for the treatment of PSCCB. Clinical trials including large series of PSCCB are needed to increase our knowledge.
\end{abstract}

\section{Introduction}

Primary pure squamous cell carcinoma of the breast (PSCCB) is an extremely rare condition, accounting for an estimated $0.04-0.075 \%$ of all breast malignancies [1]. In the literature, only some small series were reported [2-5]. The largest single series reported by Wargotz and Norris [5] included 22 cases of PSCCB. Macia et al. [6] defined criteria for pure squamous cell carcinoma. The diagnosis is established when squamous cell carcinoma is the only malignancy found in the breast specimen, metastases from 
another primary are excluded, and the tumor does not originate from the skin of the breast. Not only the pathogenesis but also the clinical behavior and treatment for this type of tumor are controversial. Some studies suggested that it is not different from breast cancer in general [7-8] and should therefore be treated the same way. Hennessy et al. [9] regarded PSCCB as an extremely aggressive disease associated with frequent locoregional and distant relapses and resultant death. Better therapy is therefore needed to improve patients' outcome $[9,10]$. In the literature, several patients with locoregional and distant metastasis were successfully treated using cisplatin-based regimens [11-13]. I encountered a patient with PSCCB who underwent a mastectomy and developed local recurrence less than 1 month after surgery. She responded well to cisplatin-based chemotherapy.

\section{Case Presentation}

A 50-year-old woman presented with a large right breast mass of 4 months duration. There was no family history of breast cancer. Physical examination showed a solid mass, $10 \times 9 \mathrm{~cm}$ in size, in the upper outer quadrant of the right breast. The overlying skin was erythematous, nodular, and ulcerated with a 2-cm satellite nodule at the areola. There was neither a retracted nipple nor excretion from the nipple. Mammograhy revealed an oval mass with well-defined but irregular borders without calcification, approximately $10 \mathrm{~cm}$ in its greatest dimension (fig. 1). The radiologist classified the mass as malignant. The left breast was negative on palpation and mammography. On February 6, 2012, a core-needle biopsy was performed and the diagnosis of an invasive ductal carcinoma was suggested. The patient's laboratory data, including routine blood chemistry and complete blood count with differential diagnosis, were within normal limits.

She underwent 4 courses of neoadjuvant therapy using cytoxan, epirubicin and fluorouracil. Neoadjuvant therapy was ineffective. She had a modified radical mastectomy and lymph node dissection on April 23, 2012. On May 21, 2012, when she returned to the clinic, 3 recurrent tumor nodules were found near the lower surgical margin. Chemotherapy using cisplatin and taxotere was started. She responded very well to the therapy. The subcutaneous nodules almost completely regressed when she was seen on September 11, 2012.

\section{Histopathology}

The tumor measured $10 \times 9 \mathrm{~cm}$ in size. The cut surface of the mass was grayish-tan to pink-yellow, lobulated, and exhibited extensive necrosis with a cavity containing brownish turbid fluid. The tumor mass extended to and ulcerated the skin (fig. 2). Microscopically, the tumor was composed of entirely malignant squamous cells with intercellular bridges and cytoplasmic keratinization. In focal areas, keratin pearls were found (fig. 3 , fig, 4 ). Angiolymphatic as well as perineural invasion was observed. Three lymph nodes were found to have metastasis. Immunohistochemical staining revealed negative estrogen and progesterone receptors. Her2/neu was 2+. The FISH test for Her2/neu gene amplification was negative and epithelial growth factor receptor (EGFR) was positive.

\section{Discussion}

PSCCB is a rare pathologic condition. Surgery is usually the initial treatment. In some cases, a complete excision of the tumor may be enough, while in other cases a mastectomy is required. It could be argued that axillary lymph node dissection might be omitted except in cases with palpable nodal disease. This is supported by the finding that most cases (70\%) of PSCCB do not have a nodal involvement [14].

Because of its rarity, the most appropriate therapeutic regimen is still unclear. Literature reporting the role of neoadjuvant therapy is scarce. A case of PSCCB reported 
by Takahashi et al. [15] showed progression of the disease while on neoadjuvant treatment with adriamycin (doxorubicin) and taxotere. Hennessy et al. [9] also reported no benefit to neoadjuvant therapy using antracycline/taxane-based regimens. In my patient, neoadjuvant therapy with cytoxan, epirubicin, and fluorouracil was also ineffective. In contrast, a remarkable response was reported in a patient who received neoadjuvant therapy using cisplatin and 5-flourouracil [11].

As a result of lack of data, the issue of what postoperative adjuvant treatment to prescribe for PSCCB remains unsolved. The patient reported by Murialdo et al. [12] received adjuvant therapy using cisplatin and 5 -fluorouracil for metastatic disease. She was disease-free for 28 months after surgery. In my case, the patient had local recurrence 3 weeks after surgery. She responded very well to chemotherapy using cisplatin and taxotere. Her subcutaneous nodules completely regressed 4 months after therapy. In another report, metastasis from PSCCB was successfully treated using cisplatin + fluorouracil adjuvant therapy $[12,13]$.

In conclusion, PSCCB is a rare and aggressive disease associated with frequent locoregional and distant relapses and resultant death. Better systemic therapy is therefore needed to improve patients' outcome. At this point, there is circumstantial evidence that cisplatin-based regimens may be a promising option for the treatment of PSCCB. Clinical trials including large series of these rare tumors are needed to increase our knowledge. In view of the high frequency of overexpression of EGFR, the use of anti-EGFR therapy should be explored.

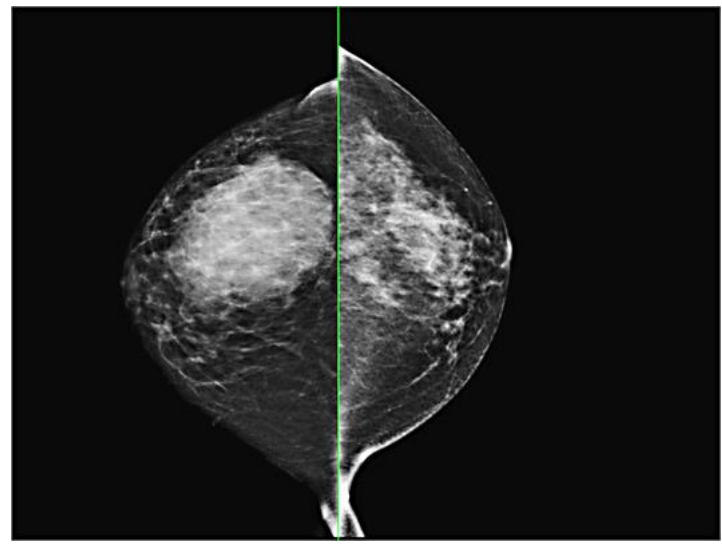

Fig. 1. Mammography showing a homogeneous large mass with irregular borders. 


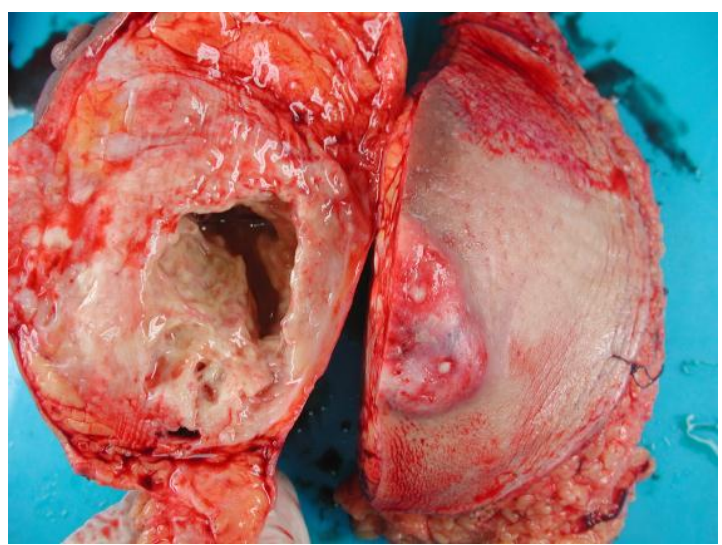

Fig. 2. Photograph of the tumor with a large cystic area (left half) and ulcerated skin (right half).

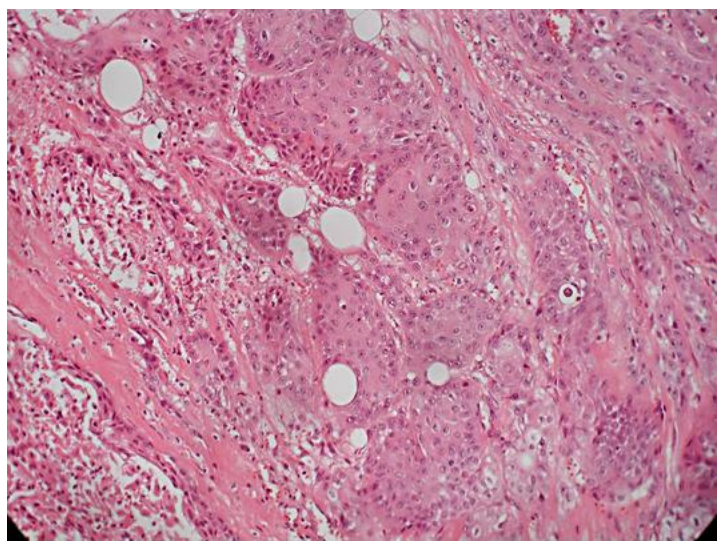

Fig. 3. Microscopic section of the tumor showing clusters of malignant squamous cells with intercellular bridges and cytoplasmic keratinization. H\&E stain, $\times 200$.

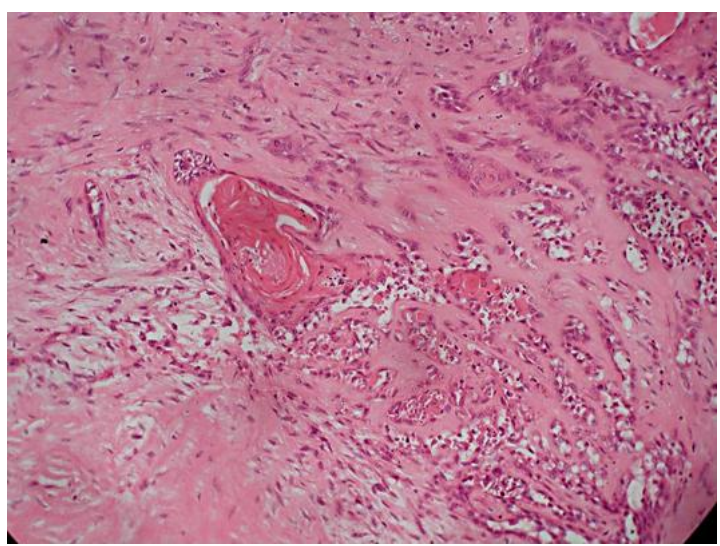

Fig. 4. Microscopic section of the tumor showing formation of keratin pearls. H\&E stain, $\times 200$. 


\section{References}

1 Weigel RJ, Ikeda DM, Nowels KW: Primary squamous cell carcinoma of the breast. South Med J 1996;89:511-515.

-2 Gupta G, Malani AK, Weigand RT, Rangineni G: Pure primary squamous cell carcinoma of the breast: a rare presentation and clinicopathologic comparison with usua ductal carcinoma of the breast. Pathol Res Pract 2006;6:465-469.

-3 Behranwala KA, Nasiri N, Abdullah N, Trot PA, Gui GP: Squamous cell carcinoma of the breast: clinicopathologic implications and outcome. Eur J Surg Oncol 2003;29:386-389.

-4 Wrightson WR, Edwards MJ, McMasters KM: Primary squamous cell carcinoma of the breast presenting as a breast abscess. Am Surg 1999;65:1153-1155.

5 Wargotz ES, Norris HJ: Metaplastic carcinoma of the breast. IV. Squamous cell carcinoma of ductal origin. Cancer 1990;65:272-276.

6 Macia M, Ces JA, Becerra E, Novo A: Pure squamous cell carcinoma of the breast: report of a case diagnosed by aspiration cytology. Acta Cytol 1989;33:201-204.

7 Cappellani A, Di Vita M, Zanghì A, De Luca A, Tomarchio G. La Porta D, Lanzafame S, Alfano G: A pure primary squamous cell breast carcinoma presenting as a breast abscess: case report and review of literature. Ann Ital Chir 2004;75:259-262; discussion 262-263.

8 Rosen PP (ed): Rosen's Breast Pathology, 2 ed. Philadelphia, Lippincott-Raven, 1997.

9 Hennessy BT, Krishnamurthy S, Giordano S, Buchholz TA, Kau SW, Duan Z, Valero V, Hortobagyi GN: Squamous cell carcinoma of the breast. J Clin Oncol 2005;23:7827-7835.

10 Aparicio I, Martinez A, Hernández G, Hardisson D, De Santiago J: Squamous cell carcinoma of the breast. Eur J Obstet Gynecol Reprod Biol 2008;137:222-226.

-11 Dejager D, Redlich RN, Dayer AM, Davis HC, Komoroski RA: Primary squamous cell carcinoma of the breast: sensitivity to cisplatinum-based chemotherapy. J Surg Oncol 1995;59:199-203.

12 Murialdo R, Boy D, Musizzano Y, Tixi L, Murelli F, Ballestrero A: Squamous cell carcinoma of the breast: a case report. Cases Journal 2009;2:7336-7339.

13 Hiramatsu K, Kato K, Hirata A, Matusba H, Hara T, Ito T, Miyata T, Akagawa T, Kutsuna Y, Machiki Y, Fujioka S: A resected case of squamous cell carcinoma of the breast successfully treated by FU plus cisplatin (CDDP) adjuvant therapy against recurrent metastases (in Japanese). Gan To Kagaku Ryoho 2007;34:443-446.

14 Cardoso F, Leal C, Meira A, Azevedo R, Mauricio MJ, Leal da Silva JM, Lopes C, Pinto Ferreira E: Squamous cell carcinoma of the breast. Breast 2000;9:315-319.

-15 Takahashi T, Akashi-Tanaka S, Fukutomi T, Watanabe T, Katsumata N, Miyakawa K, Hasegawa T, Tsuda $\mathrm{H}$ : Two special types of breast cancer presenting as progressive disease after neoadjuvant chemotherapy with docetaxel plus doxorubicin. Breast Cancer 2001;8:234-237. 